\title{
INOVASI PEMANFAATAN PUPUK ORGANIK RAMAH LINGKUNGAN UNTUK MENINGKATKAN PRODUK SAYURAN YANG BERNILAI EKONOMIS
}

\author{
Mulyati'), Soesetio R. MF. A(1), Afriadin'), Sefiana R. R. ${ }^{1)}$, Sabrina A. ${ }^{1)}$, Paksindra R. ${ }^{1)}$ \\ ${ }^{1)}$ Program Studi Ilmu Tanah, Fakultas Pertanian, Universitas Mataram, Mataram, NTB, Indonesia \\ Corresponding author : Mulyati \\ Email: yatimulyati@unram.ac.id
}

Diterima 03 September 2021, Direvisi 13 September 2021, Disetujui 13 September 2021

\begin{abstract}
ABSTRAK
Tujuan kegiatan pengabdian kepada masyarakat (PKM) ini adalah untuk meningkatkan pengetahuan dan pelatihan kepada petani sayuran melalui teknik meramu media berbasis standar budidaya pertanian yang baik atau "Good Agriculture Practices", dan sekaligus memperkenalkan konsep budidaya sayuran melalui pemanfaatan pupuk organik yang ramah lingkungan. Kegiatan PKM ini dilaksanakan dengan metode pendekatan Participatory Rural Appraisal (PRA) dengan melibatkan anggota kelompok tani, ketua kelompok tani, Penyuluh Pertanian setempat, ketua dan anggota Karang Taruna, tokoh masyarakat dan beberapa staf desa. Hasil kegiatan PKM ini menunjukkan bahwa adanya peningkatan pemahaman peserta tentang teknik pembuatan pupuk organik dari berbagai limbah pertanian untuk meningkatkan kesuburan tanah dan meramu media tanam untuk meningkatkan produksi sayuran organik. Secara umum, peserta PKM sangat antusias dan memberikan respon yang positif terhadap materi yang disampaikan dan bersedia menerapkan penggunaan pupuk organik ramah lingkungan tersebut dalam teknik budidaya sayuran organik dilahan pertaniannya. $\mathrm{Di}$ akhir sosialisasi dan pelatihan ini peserta berharap dapat diberikan pendampingan secara berkelanjutan dari mahasiswa KKN Universitas Mataram.
\end{abstract}

Kata kunci : inovasi; pupuk organik; sayuran; nilai ekonomis.

\begin{abstract}
The objective of this Community Service Activity (PKM) is to increase knowledge and training to vegetable farmers through the technique of combining various waste material as plant growth media based on good agricultural cultivation standards or "Good Agriculture Practices", and at the same time introduce the concept of vegetable cultivation through the use of Environmentally Friendly organic fertilizers. This Community Service Activity is carried out by Participatory Rural Appraisal (PRA) approach method by involving members of farmers groups, farmers group chairmen, local Agricultural Extension, chairmen and members of Karang Taruna, community leaders and some village staff. The results of this PKM activity showed that there was an increased understanding of participants understanding of organic fertilizer manufacturing techniques from various agricultural wastes to increase soil fertility and concoct planting media to increase organic vegetable production. In general, PKM participants are very enthusiastic and give a positive response to the material delivered and are participants are willing to apply the use of environmentally friendly organic fertilizers in organic vegetable cultivation techniques in their farms. At the end of this socialization and training participants hope to be provided with ongoing assistance from KKN students of Mataram University.
\end{abstract}

Keywords: innovation; organic fertilizers; vegetables; economic value.

\section{PENDAHULUAN}

Sektor pertanian hingga saat ini masih merupakan sektor yang strategis dan sebagian besar mata pencaharian masyarakat di Nusa Tenggara Barat khususnya Pulau Lombok adalah di bidang pertanian. Potensi di bidang pertanian ini masih cukup tinggi dalam memberikan peningkatan pendapatan kepada masyarakat. Pendapatan ini akan lebih baik lagi jika dalam teknik budidaya pertanian idberikan sedikit sentuhan teknologi, diimbangi dengan penyediaan inovasi teknologi pertanian yang sesuai dengan kondisi biofisik, sosial dan budaya petani setempat. Oleh karena itu petani harus mampu mengenali kondisi biofisik lahan yang akan dikelola, agar produktivitas lahan dapat ditingkatkan. Dan pada gilirannya dapat meningkatkan pendapat dan kesejahteraan petani dan keluarga. 
Produk hortikultura seperti sayuran organik makin banyak digemari masyarakat deiring dengan munculnya kesadaran masyarakat akan pentingnya hidup sehat dengan mengkonsumsi produk pertanian terutam sayuran yamh bebas dengan bahanbahan agrokimia baik berupa pupuk anorganik maupun pestisida. Desa kembang Kuning merupakan suatu desa yang terletak di kaki Gunung Rinjani, beriklim sejuk terdapat aiar yang berkelimpahan dan tanah yang subur, sehingga desa in juga merupakan desa yang potensial untuk dikembangkan menjadi desa tujuan wisata. Pengembangan wisata di tempat ini sudah mulai diminati oleh wisatawan lokal maupun pancanegara. Di kiri kanan jalan banyak terlohat penginapan-penginapan dan home stay yang dimiliki masyarakat. Wisatawan ini banyak membutuhkan sayuran segar setiap harinya. Oleh karena itu, desa ini yang memiliki tanah yang cukup subur dan terdapat sumber air yang berlimpah maka pengembangan sayuran organik mempunyai prospek yang sangat baik.

Secara umum petani di desa tersebut sudah banyak melakukan budidaya sayuran, namun sayuran yang dihasilkan belu bersifat organik karena umumnya budidaya sayuran dilakukan secara intensif dengan menggunakan pupuk anorganik yang beranalisis tinggi dan mengatasi organisme pengganggu tanaman dengan menggunakan pestisida. Pemakaian pupuk anorganik beranalisis tinggi dan penyemprotan pestisida yang intensif menungkinkan terjadinya penimbunan bahan-bahan agrokimia di dalam jaringan tanaman, dan pengaruh residu dari bahan agrokimia ini sangat membahayakan kesehatan kosumen, Lama kelamaan penggunaan pupuk dan pestisida menjadi tidak efisien Beradasarkan hal-hal tersebut perlu dicari suatu upaya agar petani sayuran di desa Kembang Kuning dapat memahami kondisi biofisk lahan yang dimiliki, mampu memilih jenis sayuran yang bernilai ekonomis tinggi dan teristimewa produk sayuran yang dihasilkan tidak mengandung efek residu dari penggunaan pupuk dan pestisida yang berlebihan.

Salah satu cara untuk mengurangi penggunaan pupuk anorganik adalah dengan cara mensubstitusi penggunaan pupuk anorganik dengan pupuk organik yang ramah lingkungan (environmentally friendly). Pertanian yang ramah lingkungan ini seringkali disebut pertanian yang berkelanjutan (sustainable agriculture). Melalui pertanian organik yang ramah lingkugan ini diharapkan dapat tercipta suatu sistem pertanian yang tanpa sisa (zero waste farming system), seperti menggunakan pupuk kandang, dan kompos yang berasal dari limbah pertanian. Dalam proses pembuatan pupuk organik ini agar diperkaya denga pupuk hayati/ biofertilizer (Goenadi, 2006).

Penggunaan limbah pertanian untuk kompos dan pupuk kandanag ini dapat meningkatkan bahan organik tanah, dan produktivitas tanah dapat ditingkatkan, sekalaigus kualitas produk sayuran organik yang dihasilkan lebih sehat dan mempunyai nilai gizi yang lebih tinggi, yang pada gilirannya sayuran organik yang dihasilka memiliki nilai jual yang lebih tinggi. Kecuali terhadap produk yang dihasilkan pemanfaatan pupuk kandang dan kompos ini juga dapat memperbaiki sifat fisik seperti meningkatkan statilitas agregat tanah, kemampuan tanah memegang air (water holding capacity). Selain tu, juga dapat berperan terhadap kapasitas tukar kation (cation exchange capacity) yang merupakan terminal hara sebelum dimanfaatkan oleh tanaman, dan juga terhadap sifat biologi tanah yaitu yang mampu mendukung terciptanya kondisi yang menguntungkan bagi pertumbuhan dan perkembangan mikroorganisme dalam tanah.

Lahan pertanian di desa Kembang Kuning Kecamatan Sikur Kabupaten Lombok Timur ini merupakan tanah yang cukup subur, ketersediaan air yang cukup, memungkinkan petanian dapat dilaksanakan dengan intensif, namun petani setempat tidak memanfaatkan kotoran hewan dan limbah-limbah pertanian yang ada disekitarnya untuk meningkatkan produksi sayuran. Kendala yang lain adalah kurangnya minat petani untuk menanam jenis sayuran lain yang lebih mempunyai nilai ekonomis yang lebih tinggi. Untuk pertumbuhan sayuran, petani umumnya hanya menggunakan pupuk anorganik, hal ini menyebabkan pertanian di tempat ini tidak ramah lingkungan dan tidak berkelanjutan. Dengan demikian diharapkan petani dapat mulai memanfaatkan limbah organik seperti dari pertanian dan hewan yang ada di sekitarnya, sehingga pertanian secara berkelanjutan dapat terus terjamin, dan kualitas sayuran organik leebih baik dan lebih sehat untuk konsumen.

Untuk mendapatkan kualitas pupuk organik yang baik, maka limbah pertanian dan kotoran hewan yang akan diaplikasikan perlu mendapatkan perlakuan terlebih dahulu yaitu dengan memberikan biofertilizer EM-4 dan Trichoderma harzianum (Mulyati dan Lolita, 2006). Pemberian pupuk hayati (biofertilizers) ini dimaksudkan untuk mempercepat proses dekomposisi, produktivitas tanah dapat ditingkatkan. dan pada gilirannya kualiatas 
sayuran menjadi lebih baik, sehingga pertumbuhan sayuran yang bernilai ekonomis menjadi lebih baik dan dapat meningkatkan pendapatan petani dan memberikan kesejahteraan bagi rumah tangga petani.

Tujuan utama dari kegiatan pengabdian kepada masyarakat ini adalah untuk mensosialisasikan tentang penggunaan pupuk organik untuk jenis tanaman hortikultura terutama sayuran yang mempunyai nilai ekonomis seperti selada, pakcoy, kol bunga dan brokoli; untuk meningkatkan pengetahuan dan pengalaman kepada petani sayur di Desa Kembang Kuning, Kecamatan Sikur, Kabupaten Lombok Timur mengenai teknik pembuatan pupuk organik, dan teknik mengelola media untuk pertumbuhan sayuran yang ramah lingkungan, yang dapat menjamin kelanjutan usahatani sayuran Hasil kegiatan pengabdian kepada masyarakat ini diharapkan dapat bermanfaat bagi banyak pihak. Selain manfaat lansung bagi petani sasaran, hasil dari kegiatan dapat dijadikan refrensi untuk diterapkan/diperluas penerapannya pada kelompok tani sayuran lain di Pulau Lombok maupun daerah lain. Bagi Pemda setempat, kegiatan ini dapat dijadikan sebagai salah satu upaya untuk mempercepat keberhasilan program pengembangan tanaman hortikultura khususnya sayuran yang sekaligus dapat menunjang wisata di desa tersebut dan pendapatan masyarakat tani. Bagi tim pelaksana Unram, kegiatan ini merupakan sarana untuk menambah pengetahuan/ wawasan mengenai masalah on farm dan cara menanganinya yang tepat, serta proses pembelajaran bagi mahsiswa yang dilibatkan dalam kegiatan ini.

\section{METODE}

Kegiatan PPM ini dilaksanakan di Desa Kembang Kuning Kecamatan Sikur Kabupaten Lombok Timur, Pebyuluhan dilakukan dengan metode ceramah dengan menggunakan alat bantuberupa gambargambar, slide show melalui LCD dan demplot di lahan petani. Ceramah diakhiri dengan diskusi, tanya jawab dan tukar menukar pengalaman antara penyuluh dan peserta. Materi penyuluhan berisikan aspek inovasi teknologi pertanian seperti pembuatan pupuk organik dan aplikasinya pada sistem pertanian organik, guna mendapatkan produk sayuran yang berkualitas dan bernilai tinggi.

Selain itu, juga dengan Participatory Rural Appraisal (PRA), yang artinya melibatkan petani peserta kegiatan pengabdian mulai dari perencanaan, pengumpulan bahan baku kotoran hewan untuk pupuk kandang yang berbasis standar budidaya pertanian yang baik atau "Good Agriculture Practices". Bimbingan teknis dari tim pelaksana pengabdian kepada masyarakat dilakukan langsung di lapang, Pada akhir kegiatan dilakukan evaluasi tentang respon /pendapat peserta tentang materi yang disampaikan dalam penyuluhan. Tahap berikutnya, kepada petani yang siap menerapkan usahatani sayuran untuk pendampingan langsung oleh tenaga penyuluh dan peneliti dari Unram. Sebagai meteri tambahan juga diberikan teknik bercocok tanam berbagai sayuran melalui pemanfaatan pupuk organik dengan model usahatni sehat juga diberikan beberapa macam bibit sayuran seperti selada, caisim, pakcoy, cabe merah, kol bunga, bayam dan lain-lain.

\section{HASIL DAN PEMBAHASAN \\ Kegiatan Sosialisasi dan Penyuluhan}

Sosialisasi kegiatan pengabdian kepada masyarakat ini diawali dengan survei lokasi untuk menentukan tempat kegiatan penyuluhan, untuk praktik pembuatan pupuk organik dan aplikasi pada tanaman sayuran. Penyampaian materi penyuluhan dilakukan di kantor desa dengan matei sosialisasi konsep model usahatani terpadu dengan memanfaatkan limbah pertanian sebagai bahan dasar pembuatan pupuk organik untuk menghasilkan produk sayuran yang sehat dan bebas bahan agrokimia seperti yang berasal daru pupuk dan pestisida.

Setelah penentuan lokasi kegiatan, dan kesepakatan pelaksanaan kegiatan, maka dilakukan pembentukan Fokus Discussion Group (FGD), dan melakukan pembagian tugas untuk pengadaan limbah pertanian. seperti jerami, pupuk kandang dan EM-4 oleh tim penyuluh. Kegiatan ini dilaksanakan dalam bentuk penyuluhan melalui pertemuan langsung dengan peserta yang terdiri atas ketua dan anggota kelompok tani, kepada desa dan staf, tokoh masyarakat, karang taruna dan juga pemuka-pemuka masyarakat.

Untuk memperlancar proses praktik pembuatan pupuk organik, maka dibentuk tim fasilitator yang terdiri atas mahasiswa KKN tematik desa Kembang Kuning dan dibantu oleh alumni Fakultas Pertanian yang bekerja sebagai penyuluh pertanian di Kecamatan Sikur Lombok Timur. Tahap pertama yang dilakukan adalah penyiapan limbah pertanian yang dijadikan pupuk organik yang dipersiapkan mahasiswa dan peserta kegiatan pengabdian kepada masyarakat, dengan langkah-langkah sebagai berikut : 


\section{Penyiapan limbah pertanian}
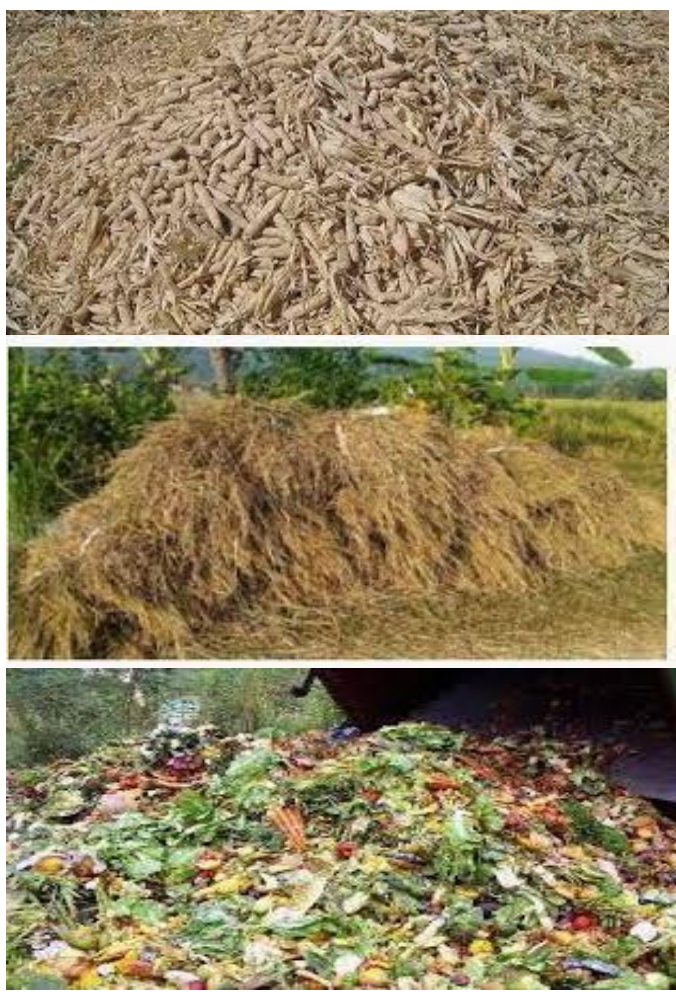

Gambar 1. Limbah pertanian jerami

padi, tongkol jagung, dan rumah tangga

Pembuatan pupuk organik yang berasal dari limbah pertanian yang telah terkumpul tadi kemudian ditambahkan dengan pupuk hayati (biofertlizer). Beberapa jenis pupuk hayati yang banyak beredar di pasaran dapat digunakan EM-4, Azotobacter, bakteri pelarut fosfat seperti species dari Bacillus, Pseudomonas, Aspergillus, mikoriza dan sebagainya. Selain itu juga dapat digunakan mikroba perombak selulosa seperti Trichoderma dan Penicillium

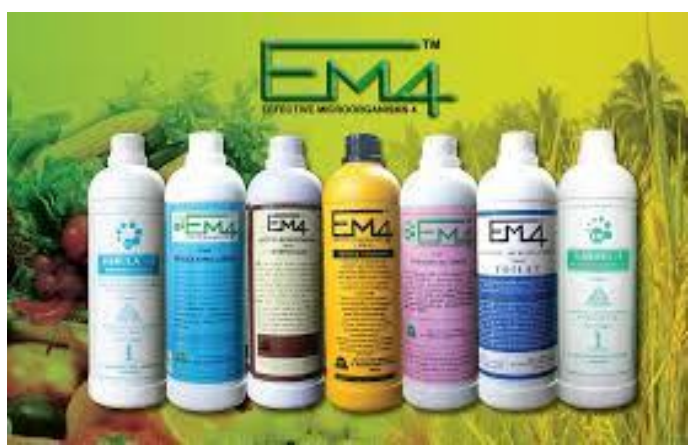

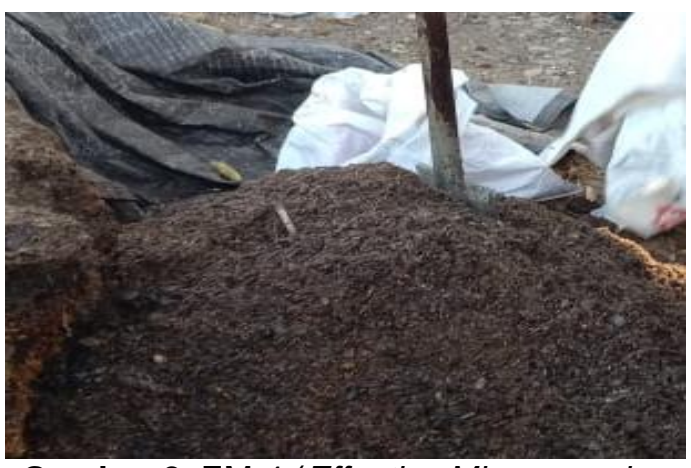

Gambar 2. EM-4 (Effective Microorganism dan pupuk organik yang siap digunakan

\section{Tahap pengolahan tanah dan penanaman}

Sebelum penanaman tanaman sayuran yang bernilai ekonomis terlebih dahulu dilakukan pengolahan tanah dan aplikasi pupuk organik. Ukuran petak dibuat dengan lebar 1 meter dan panjang dapat disesuaikan dengan kondisi lapangan. Hal ini dimaksudkan agar pemeliharaan tanaman dapat dilakukan dengan mudah, terutama pada saat penyiangan dan panen.

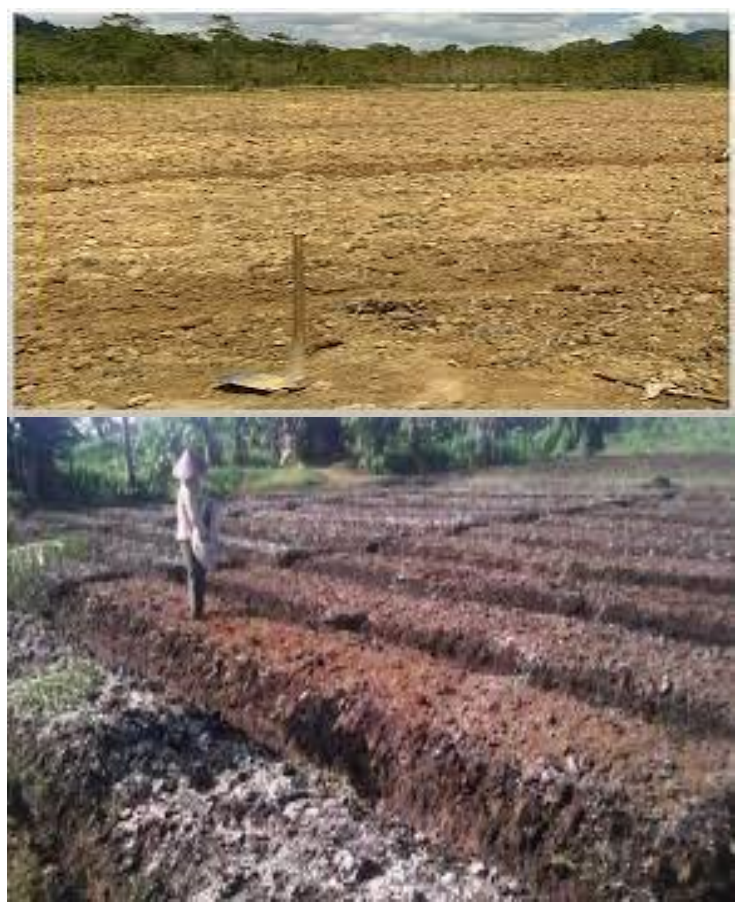

Gambar 3. Pengolahan tanah dan pembuatan petak percobaan.

Penanaman jenis tanaman yang dipilih adalah tanaman selada, karena keterbatasan waktu yang dimiliki sehingga tidaklah mungkin untuk menanam semua jenis tanaman yang memiliki nilai ekonomis 


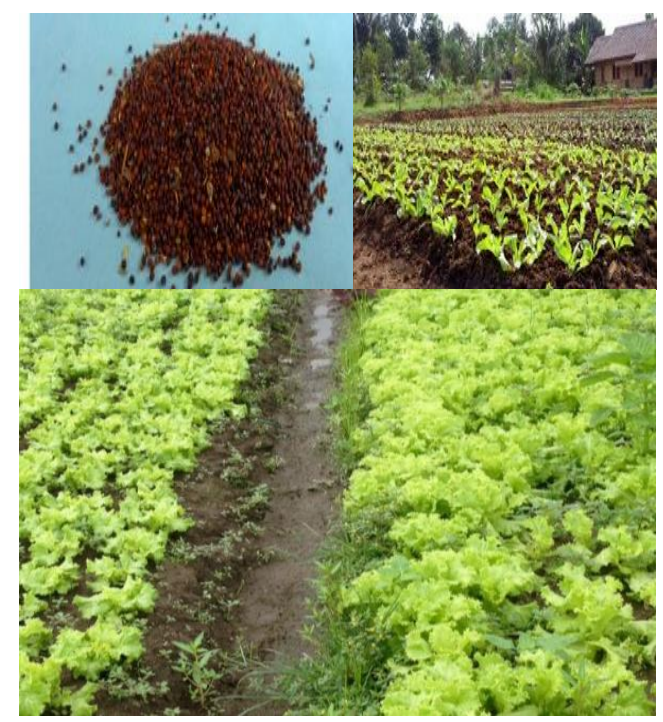

Gambar 4. Benih dan pindah tanam bibit tanaman selada, pertumbuhan selada yang siap panen.

Tanaman-tanaman yang mempunyai nilai ekonomis tinggi lain yang banyak diminati oleh wisatawan sebagai contoh: caisim, tomat ,kol bunga dan brokoli. Tapi untuk tujuan demplot, tidak semua tanaman dapat ditanam pada saat KKN tematik dilaksanakan mengingat waktu $\mathrm{KKN}$ juga yang sangat singkat.

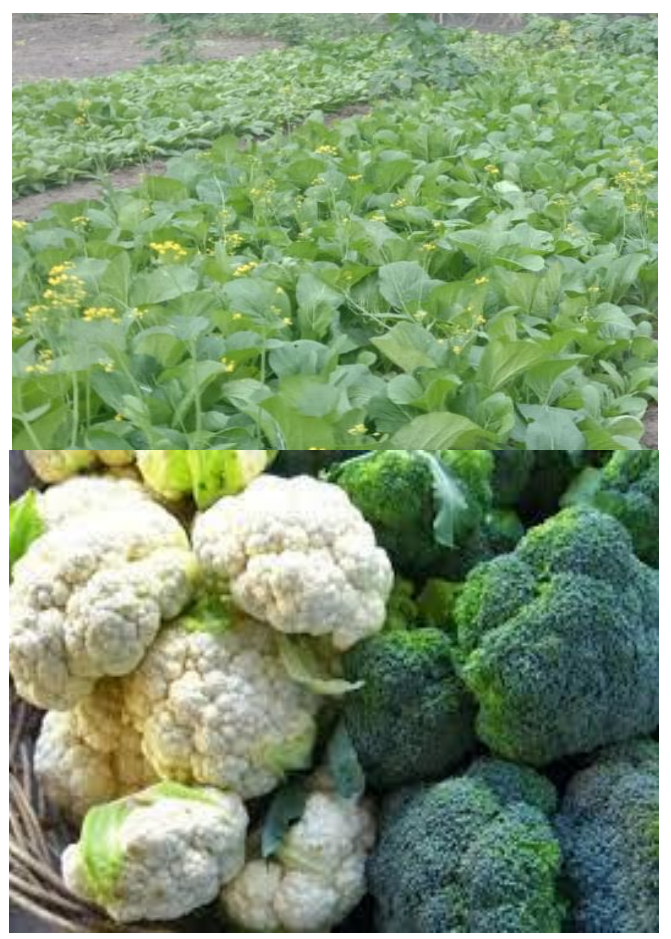

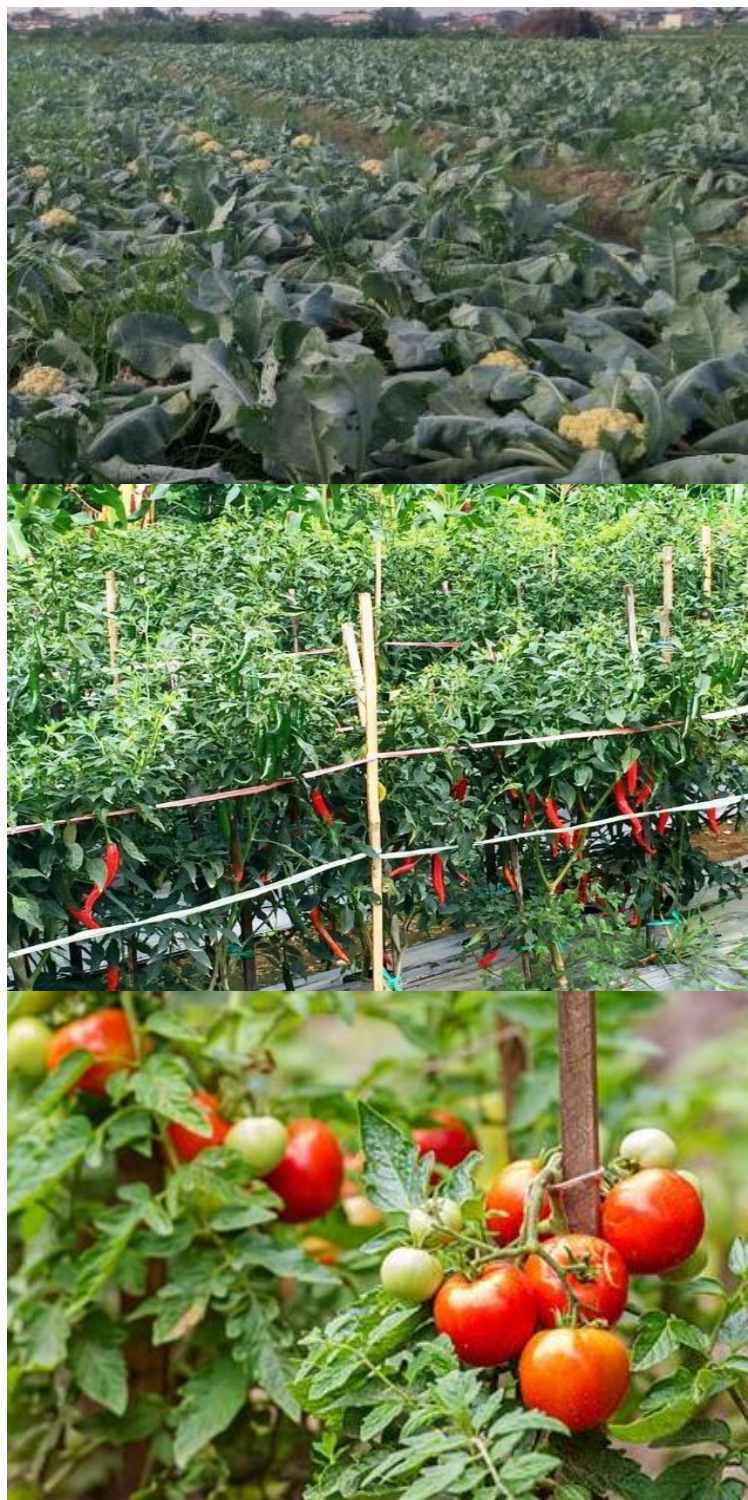

Gambar 5. Tanaman lain yang mempunyai nilai ekonomis lainnya.

\section{Model Usaha tani sehat}

Konsep model usahatani sayuran sehat yang bebas residu kimia dan aplikasi teknologi dijelaskan oleh tim penyuluh yang terdiri atas mahasiswa KKN dan penyuluh pertanian Kecamatan Sikur peserta (petani sayuran) secara lansung dengan menggunakan slide yang berisi gamba-gambar dan ditayangkan melalui LCD. Pada prinsipnya, konsep bertani sehat tersebut dimaksudkan untuk menangani masalah teknis usahatani sayuran secara terpadu dan sinergis, terutama yang berkaitan dengan pemenuhan kebutuhan unsur hara dan pengendalian hama penyakit yang tidak menggunakan pestisida, atau dengan menggunakan pestisida nabati yang bahan bakunya berasal dari tumbuhan lokal. Dengan demikian semua didasarkan pada konsep usahatani sehat dan bebas residu kimia. 
Berdasarkan hasil evaluasi kegiatan pengabdian yang dilaksanakan tim penyuluh, dengan cara mengamatii partisipasi peserta penyuluhan dalam berinteraksi dengan peserta lainnya dan tim penyuluh selama kegiatan berlansung,ternyata respon peserta terhadap materi sngat tinggi. Keberhasilan hasil kegiatan ini dievaluasi melaui jumlah kehadiran peserta dalam setiap kegiatan dari pengumpulan bahan, pembuatan pupuk organik dan teknik aplikasinya ; keseriusan peserta dalam mengikuti penyampaian teori atau penjelasan maateri; banyaknya pertanyaan-pertanyaan, yang berarti peserta dapat menyerap materi yang diberikan dengan baik. Dari semua yang terpenting adalah materi penyuluhan diyakini sangat bermanfaat dan akan diterapkan dalam teknik budidaya sayuran yang sehat dan bebas residu pupuk dan pestisida.

Dari sini jua, petani dapat mengerti dan paham bahwa segala sesuati yang dihasilkan dari kegiatan usatani mereka sekalipun itu limbah yang nampaknya tidak berguna, tetapi apabila dikelola dengan tepat dan benar masih dapat dipergunakan untuk sesuatu yang lebih berhasil guna dan lebih berdaya guna. Tim penyuluh juga menjelaskan tentang pentingnya model usahatani terpadu tanpa limbah atau zero waste.

\section{Respon/Tanggapan Petani}

Secara umum, tanggapan petani peserta kegiatan pengabdian kepada masyarakat ini sangat positif, mereka sangat antusias untuk segera menerapkan konsep yang disampaikan pada pertemuan tersebut. Selama ini, petani sayuran di desa Kembang Kuning Kecamatan Sikur Kabupaten Lombok Timur tidak pernah mendapatkan pencerahan atau bimbingan teknis di lapangan secara langsung dari pihak (dinas) terkait atau pihak lain, sehingga mereka tidak tahu apa yang harus diperbuat untuk menangani permasalahan usahatani sayuran organik yang mereka lakukan, terutama masalah keseimbangan hara di dalam media tanam dan pemanfaatan limbah pertanian menjadi pupuk organik, dan bagaimana upaya memperkaya hara pada pupuk organik yang dihasilkan serta teknik yang dapat mempercepat pengomposan limbah pertanian menjadi pupuk organik.

Peserta menunjukkan antusiasme yang tinggi, mereka sadar bahwa limbah pertanian yang keterdapatannya berlimpah di sekitar mereka masih dapat dimanfaatkan sebagai pupuk organik yang masih banyak mengandung unsur hara dan berperan dalam kontribusi hara untuk meningkatkan produktivitas tanah dan tanaman, yang aman untuk kesehatan. Selanjutnya peserta kegiatan penyuluhan ini khususnya kelompok tani setempat berharap akan terus diberikan pendampingan secara berkelanjutan.

\section{SIMPULAN DAN SARAN}

Berdasarkan hasil kegiatan pengabdian kepada masyarakat ini dapat disimpulkan bahwa kegiatan ini telah memberikan pengetahuan dan keterampilan tentang inovasi pemanfaatan limbah pertanian termasuk kotoran hewan yang dapat dijadikan pupuk organik untuk meningkatkan produktivitas tanah dan hasil sayuran. Selain itu, kegiatan pengabdian kepada masyarakat ini mempunyai peranan penting untuk petani tanaman hortikultura khususnya sayuran dalam mengembangkan usahataninya di desa Kembang Kuning. Petani menyambut baik arahan dan ajakan tim pengabdian kepada masyarakat untuk dapat menerapkan good agriculture practices (GAP) dan apliaksi pupuk organik yang ramah lingkungan sehingga dapat memberikan produksi sayuran yang berkualitas tinggi, sehat dan bebas residu bahan-bahan agrokimia kimia.

Sebagai tindak lanjut dari kegiatan pengabdian kepada masyarakat ini, maka dapat direkomendasikan agar pemerintah dapat memberikan binaan kepada masyarakat secara berkesinambungan, dan juga pendampingan kepada petani sayuran agar dapat mengimplementasikan pemanfaatan limbah pertanian menjadi pupuk organik dengan cara penambahan pupuk hayati (biofertilizers), untuk mendapatkan kualitas pupuk organik yang baik, yang pada akhirnya dapat menghasilkan sayuran yang memiliki nilai ekonomis tinggi.

\section{UCAPAN TERIMA KASIH}

Disampaikan terima kasih kepada bapak Rektor Universitas Mataram, Ketua Lembaga Penelitian dan Pengabdian Kepada Masyarakat Universitas Mataram yang telah memberikan kepercayaan kepada kami untuk membimbing mahasisiwa KKN. Dan juga kepada bapak kepala desa dan staf desa Kembang Kuning kecamatan Sikur Kabupaten Lombok Timur yang telah memfasilitasikan segaa sesuatunya hingga kegiatan ini dapat berjalan dengan baik dan lancar. Terima kasih juga kepada adik-adik mahasiswa KKN desa Kembang Kuning atas kerjasamanya yang tulus dan tidak mengenal lelah dalam pelaksanaan kegiatan pengabdian ini. 


\section{DAFTAR RUJUKAN}

Agegnehu, G., Srivastava, A.K., \& Bird, M.I. (2017). The role of biochar and biochar-compost in improving soil quality and crop performance: A review. In Applied Soil Ecology. https://doi.org/10.1016/j.apsoil.2017.06 .008.

Fisher D., \& Glaser, B. (2012). Synergisms between Compost and Biochar for sustainable soil amelioration. In Management of Organic waste. https://doi.org/10.5772/31200.

Govaerts, B., Verhulst, N., CastellanosNavarrete, A., Sayre, K.D., Dixon, J., \& Dendooven, L. (2009). Conservation agriculture and soil carbon sequestration : Between myth and farmer reality. Critical Reviews in Plant Sciences.

https://doi.org/10.1080/073526809027 76358.

Hadisuwito, S. (2008). Membuat Kompos Cair.PT Agromedian Pustaka. Jakarta, $50 \mathrm{~h}$.

Hartatik, W., \& Setyorini, D. (2011). Pemanfaatan pupuk organik untuk meningkatkan kesuburan tanah dan kualitas tanaman.

Hidup, P. L., Hasibuan, R., Si. M., Tetap, D., \& Labuhanbatu, S. (2016). Analisis dampak limbah/ sampah rumah tangga terhadap pencemaran lingkungan hidup. IImiah.

Magrone, T., Russo, M.A., Jirillo, E. (2017). Cocoa and Dark Chocolate Polyphenol : From Biology to Clinical Application. J. Frontiers in Immunology. 2017 (8), 677-685.

Mayrowani, H. (2016). Pengembangan pertanian organik di Indonesia. Forum Penelitian Agro Ekonomi. https://doi.org/10.21082/fae.v30n2.201 2.91-108.

Mulyati, Lolita, E.S. (2006). Pupuk dan Pemupukan. Mataram University Press. Mataram. 127h.

P3LKT Unram. (2010). Penyusunan Rencana Pengembangan Lahan Kering di Kapubaten Lombok Utara 2010-2015, Kerjasama P3LKT Unram- Bappeda KLU.

Permatasari, A. R., Khasanah, L.U., \& Widowati, E. (2014). Karakterisasi karbo aktif kulit singkong (Menihot utilissima) dengan variasi jenis aktivator. Jurnal teknologi Hasil Pertanian, https ://doi.org/10.20961/jthp.v0i0.13004.
Ria, R.A., Greenberg, R. (2000). Cacao Cultivation and the Conservation of Biological Diversity. Royal Swedish Academy of Science. Ambio. Vol. 29 No.3:167-173.

Saraswai, R. (2012). Teknologi pupuk hayati untuk efisiensi pemupukan dan keberlanjutan sistem poroduks pertanian. Seminar Nasional pemupukan dan Pemulihan Lahan Terdegradasi.

Song, W., \& Guo, M (2012). Quality variation of poultry litter biochar generated at different pyrolysis. https://doi.org/10.1016/j.aap.2011.11.0 18.

Wang, G.J., Xu, Z.W., \& Li, Y. (2016). Effects of iochar and compost on mungbean growth .and soil properties in a semiarid area of Northeast China. International Journal of Agriculture and Biology. https ://doi.org?10.17957/IJAB/15.0210. 